\title{
Low dose Olanzapine in chemotherapy induced nausea and vomiting: the ideal 8 pm antiemetic?
}

\section{Introduction:}

Olanzapine - benefit in chemotherapy induced nausea and vomiting (CINV)

But sedation is often disproportionate and embarrassing

Therefore a lower dose needs exploration for CINV control, sedation and ideal time of dosing.

\section{Objectives:}

To compare the efficacy, safety and sedation produced by two doses of olanzapine in control of CINV and also to find the preferred time of dosing

\section{Methods:}

Design: Prospective, randomized, double blind and controlled study

Site: Tertiary care hospital in Eastern India.

Patients: chemotherapy naïve, consenting cancer patients receiving moderately emetogenic chemotherapy and received Ondansetron and dexamethasone.

Method: Olanzapine $5 \mathrm{mg}$ or 10 mg were added in the test and control groups respectively during day 1-3 either at daytime or evening. CINV was measured with MASCC antiemesis tool and sedation with a $100 \mathrm{~mm}$ VAS from day 1-5. MASCC antiemesis tool and sedation with a $100 \mathrm{~mm}$ VAS from day 15.
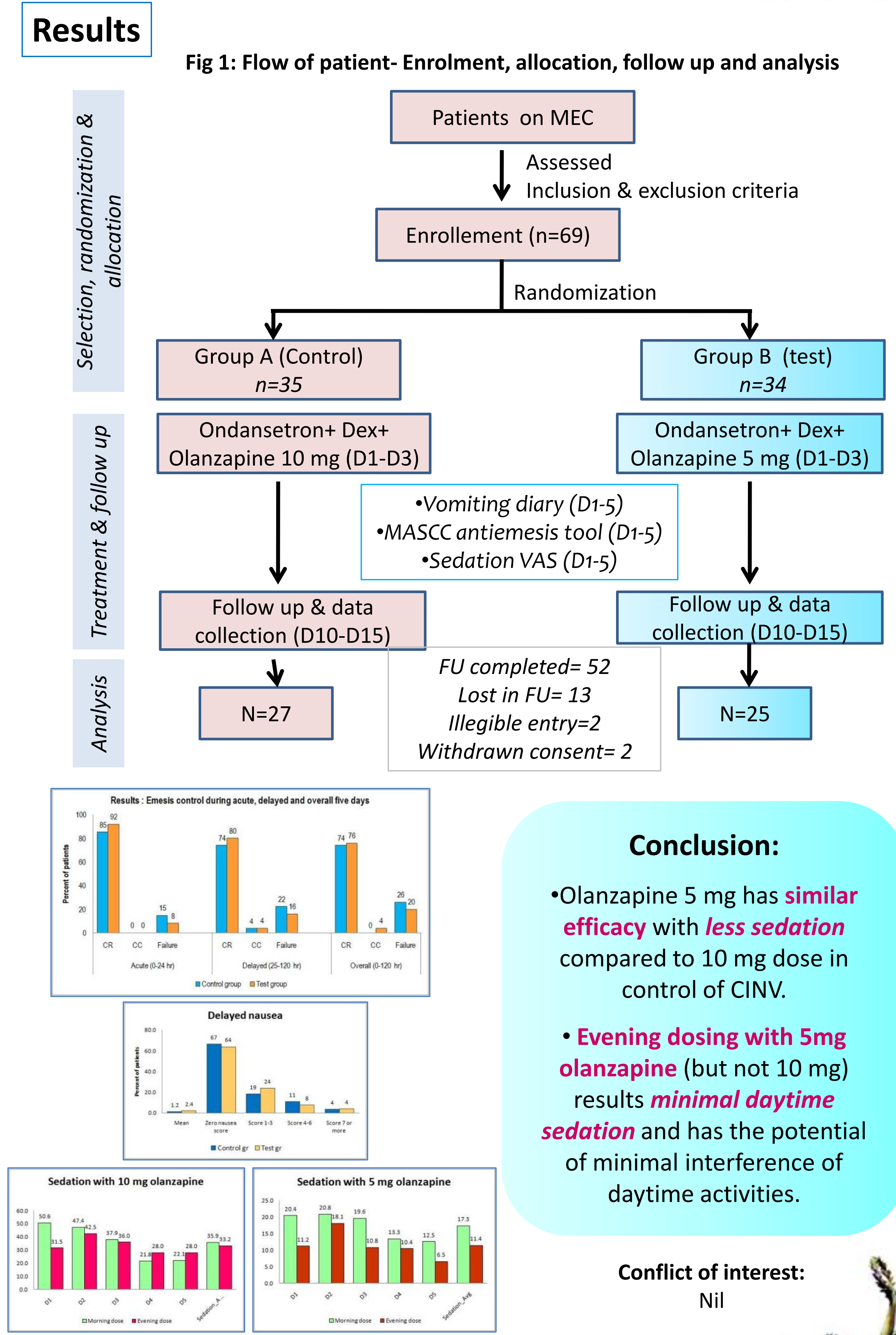

Conclusion:

- Olanzapine 5 mg has similar efficacy with less sedation compared to $10 \mathrm{mg}$ dose in control of CINV.

- Evening dosing with $5 \mathrm{mg}$ olanzapine (but not $10 \mathrm{mg}$ ) results minimal daytime sedation and has the potential of minimal interference of daytime activities.

Conflict of interest: Nil

All members of the Department of Radiation Oncology, Burdwan Medical College

\section{Contact:}

